on both dates; the plate of October 1 yielded a recognizable but not measurable star image, the limiting magnitude being $15 \cdot 5$.

There was thus magnitude loss of about $5 \mathrm{~m}$. in nine days. So rapid a fading, corresponding to a drop of intensity to one hundredth, occurs very rarely with novæ. A similar steep fall is known only with three novæ: Coronæ $(1866)^{2}$, Aurigæ $(1892)^{2}$ and Herculis $(1934)^{3}$; the decreases were $4 \cdot 2 \mathrm{~m}$. in eight days, $7.4 \mathrm{~m}$. in twenty-three days and $5 \mathrm{~m}$. in ten days, respectively. The average magnitude loss $(0.5 \mathrm{~m}$. per day) is about the same in all cases, except Nova Aurigæ $(0 \cdot 3 \mathrm{~m}$.), but the sudden fall of about $1 \cdot 5 \mathrm{~m}$. within twenty-four hours--between September 22 and 23 - is equalled only by Nova Herculis between April 3 and $4(6 \cdot 2 \mathrm{~m}$. to $7 \cdot 6 \mathrm{~m}$.). Thus Nova Cygni seems to resemble Nova Herculis, at least in this part of the light curve.

Note added in proof: On October 11 the Observatory succeeded in getting another photograph of $2 \mathrm{~h} .15 \mathrm{~m}$. exposure time on which the star image was only just visible, and the magnitude must therefore have been equal to or less than $16 \mathrm{~m}$.

George Alter.

Norman Lockyer Observatory, Sidmouth. Oet. 6.

${ }^{1}$ Huggins, Mon. Not. Roy. Ast. Soc., 52, 275 (1866).

${ }^{2}$ Harv. Ann., 81, 136/37 (1920).

${ }^{3}$ Beer, Mon. Not. Roy. Ast. Soc., 95, 538 (1935).

\section{Functions of the Research Associations}

IT is difficult to draw valid conclusions from any generalization about "industrial research". It covers a wide field of subjects and an equally wide field of quality. Depending upon the particular industry and the type and size of firm engaged in it, "industrial research" ranges from relatively minor constructional or similar developments right through to real research upon scientific fundamentals. The extent to which the latter is possible by individual firms depends so much upon the extent of the permissible expenditure that the work of the research associations tends also to cover an equally wide range.

Without doubt cases exist where criticism can be levelled at the lack of intimate knowledge of the work of the industry possessed by the staffs of the research associations. It is to meet such deficiencies that I support the suggestion of greater interchange between their staffs and those of the industrial laboratories. Such exchanges would, in my opinion, help both parties; and I would not restrict such interchange to any except the director and his immediate assistants.

Dr. Toy ${ }^{1}$ is certainly correct in his statements concerning the essential nature of confidence in the association's staff, but I feel that these staff interchanges should only help to increase such confidence by broadening the knowledge each of the others. Among many industrialists this complete confidence does not exist, particularly when it is known that the association's staff have had no personal practical contacts with the work of the industry. In these instances, the tendency is undoubtedly to confine the association's work to generalities - such as can be guided by a committee.

I do not overlook the very many original and often fundamental researches that have been completed by the research associations; but I am sure that a more free interchange of personnel would aid such work, and would help towards Sir Lawrence Bragg's aim of discovering "the best way of applying our great natural scientific ability to the strengthening of our industrial position".

Philit R. Coursey.

Nutteries,

Liss,

Hants.

${ }^{1}$ NATURE, 150, 373 (1942).

\section{A Flight of Pure Imagination}

IT is possible that the enclosed photograph and lines might not be out of place in NaTURE as a sequel to Sir Richard Paget's verses of June 15, 1935. So far as I can remember, I took the photograph some time after the year 1912 when my paper on rotating films appeared (Proc. Roy. Soc., 87) and the Rainbow

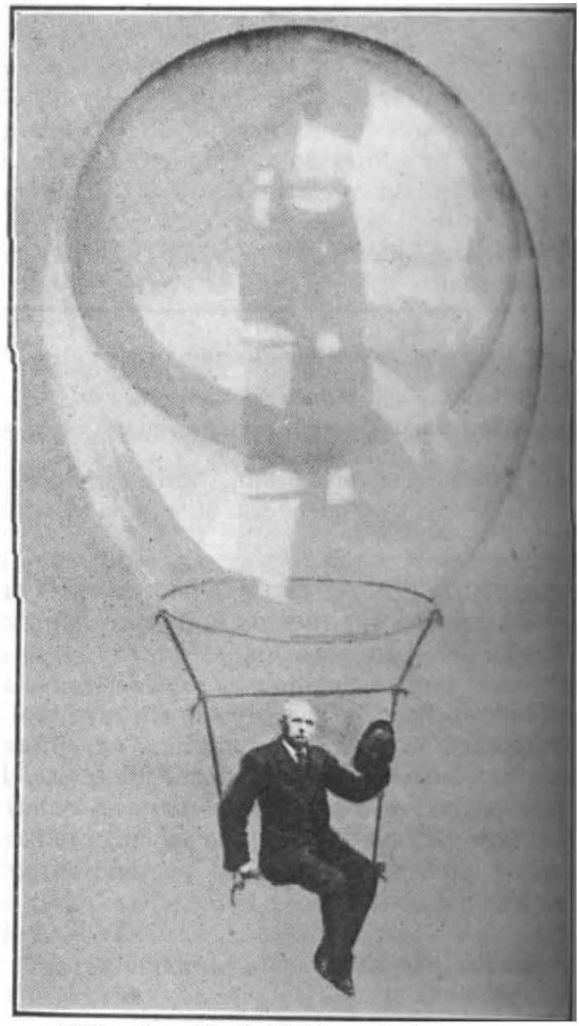

"Why does Sir C. V. Boys elect

To do the things we least expect ?"

Sir Richard gave the explanation*.

But how? Well, here's an illustration-

"A photograph which cannot lie"

A flight of pure imagination.

Cup became a popular scientific toy. I then intended to get out a third edition of my book on "Soap Bubbles" with the Rainbow Cup as the chief addition, and the idea of the fake photograph occurred to me as being a permissible diversion. Stumbling upon this at the present time, with the Paget verses fresh in memory, the seven lines with the photograph, of which three are quoted, flashed across my mind and seemed appropriate for publication. This must be my apology.

I am indebted to Messrs. Kodak Ltd. for the print from which the figure is taken, in which they have eliminated a blemish in my original negative.

* Sir Richard Paget, Natdre, June 15, 1935.

C. V. Boys. 